\title{
INTERNATIONAL REGULATION OF BIOTECHNOLOCY: PROBLEMS AND PROSPECTS
}

Introduction

Of the issues that confront modern science and the imperatives for development and human progress today, none is more controversial than biotechnology. As one author notes, within 'a few short decades, the powerful means of biotechnology have revolutionized medicine, agriculture and environmental protection'1. The potential implications of biotechnology transcend science and the environment and impact directly on the liberalisation of international trade, the protection of intellectual property rights, the right of self determination of indigenous populations and as custodians and owners of centres of biodiversity, and indeed on international relations generally. Advocates of biotechnology argue that the modification of the genetic make- up of living organisms is nothing new and that biotechnology has been part of human agricultural practices for centuries. Civen its potential financial benefits, business executives in the biotechnology industry routinely talk up its virtues as the possible panacea to the starving millions of the world, notwithstanding the general agreement that the full effect of biotechnology on humans and the environment is yet unknown. Advocates of the precautionary principle, on the other hand argue that today, the principle is an essential component of environmental policy and part of international law and that the principle should inform any regulatory approach to biotechnology. While opinions vary about the utility and indeed the propriety of biotechnology, there is a general consensus that biotechnology is set to shape the future of mankind in the coming decades. In spite of its potential impact, biotechnology has received relatively little attention from international lawyers. The little international 'law' there is on the issue is confined to a few 'soft law' instruments. Questions of biotechnology feature more as national issues meriting national regulation. Where such questions have attracted international legal attention as in international trade disputes, the issue has not been on the propriety of biotechnology regulation as such. It has generally centred on its impact on the freedom of trade. The objective in this paper is to examine the issue as to whether biotechnology is a legitimate subject for international regulation. The paper also evaluates the normative scope for any possible international regulatory framework for biotechnology.

\section{Biotechnology as an international issue}

International law is concerned with the regulation of the conduct of states in their international relations. It also regulates the conduct of other subjects in the international legal system. In this respect international law also seeks to regulate national conduct on issues which are transnational in character or are of international concern. What is it about biotechnology then that warrants international regulation? Biotechnology involves scientific technology that uses biological systems, living organisms, or related derivatives to make or modify products or processes for specific use. By its very nature, biotechnology begins and appears as a localised or national industrial issue. In spite of its 'localised' looks, the essence of biotechnology has considerable international implications which warrant international attention and regulation for several reasons.

\section{International equity}

Advocates of biotechnology argue that if allowed to develop, genetically modified organisms could be introduced into the market place for medical, pharmaceutical, agricultural, alternative fuels, and even for the protection of the environment itself. In the field of agriculture, biotechnology has the potential to alleviate a significant proportion of the problems of starvation that persist in many parts of the world and improve human lives particularly in the developing world. But if indeed biotechnology has this potential, and it does, should the international community permit only the few companies of technologically rich countries to control such an important tool? While biotechnology itself is not a global resource, it is a tool or an avenue with important implications for global resources. It is thus arguable that the philosophy underpinning the

* Professor Sam Blay is a Professor of Law, University of Technology, Sydney, Australia

1 Spranger, T, Editorial Note, Journ. Of International Biotechnology Law, Vol. 2004, 1. 
concept of the Common Heritage of Mankind (CHM) which emerged in later of part of the twentieth century could be applied to biotechnology ${ }^{2}$. The UN Ceneral Assembly adopted Resolution 2749 in 1970, declaring the CHM as the primal principle governing the exploitation of the international seabed. The CHM concept was thereafter given legal status in the 1982 Law of the Sea Convention (entered into force November 1994) as well as in the earlier 1972 UNESCO Convention for the Protection of the World Cultural and Natural Heritage and in the 1979 Moon Treaty (both already in force). The CHM as put forward by its proponents involve five basic pillars: the exclusion of sovereignty or appropriation of the resources of the deep seabed, shared management, the management of the resources for the benefit of mankind, the exclusive use of the resources for peaceful purposes and the international protection of the resources. The essence of the CHM concept is that resources of global significance cannot and should not be left for appropriation by the rich. Biotechnology is not a resource in its own right, but like the deep seabed, it provides an important access to resources that have the potential to impact on humanity. In this regard, the application of the CHM concept to biotechnology finds a rational foundation.

The idea of applying the concept of CHM to biotechnology and related issues is not new. In the late 1980 developing countries sought to apply the CHM concept to biotechnology., Hhowever, in view of the location of most of the world's 'centers of biodiversity' in the developing countries, in 1991 developing states pushed to revise the International Undertaking on Plant Genetic Resources ${ }^{3}$, so that the concept of "common heritage" was limited by the sovereignty of states over their plant genetic resources, as well as to by the rights of breeders and farmers. 4 Later in 1997 Universal Declaration on the Human Genome and Human Rights stipulated that: "[t]he human genome underlies the fundamental unity of all members of the human family, as well as the recognition of their inherent dignity and diversity".5 It further provided that the human genome is 'the heritage of humanity". More significantly, Article 4 of the Declaration also provides that "[t]he human genome in its natural state shall not give rise to financial gains".

The application of CHM to biotechnology would not, and need not preclude the patenting of drugs and new products that emerge from biotechnology. The rationale for application of CHM is to ensure that access to the mysteries of genetics is free and open to all and for the benefit of mankind.
The environmental dimension: genetic pollution

Modern biotechnology is not only complex in its sophisticated manipulation of genetics to created new product; it is also a potentially perilous journey into uncharted waters. While advocates scorn at the precautionary principle and use the principle of scientific certainty as a shield from their opponents, the reality still remains that biotechnology carries the risk of 'genetic pollution'. The issue is well summed in the view that:

concerns arise about the potential for genetic engineering to cause transnational catastrophic harm (such as destabilizing a region's biosphere through "genetic pollution"). Fears of catastrophic harm caused by biotechnology raise questions about who will bear the ultimate responsibility if such an event were to occur. Finally, there are longterm concerns about whether the widespread use of genetically modified products could accelerate the decline in global biological diversity ${ }^{6}$

The 'unity' of the global environment clearly suggests that genetic pollution in a particular region of the world is not necessarily a localized issue. On the contrary, it is an issue in which the international community has legitimate interest that warrants an international approach in regulation.

\section{The international trade dimension}

There are no accepted universal international standards for biotechnology particularly in agriculture. Given the concerns about the unknown impact of genetically modified products on the environment and for human health, many countries regard such products with suspicion and scepticism. While Tthe WTO rules permit the restriction of imports on health environmental grounds, it is not clear whether a member trading nation can impose restrictions on genetically modified products in the absence of any proof that such products cause any harm to consumers or the environment.

2 On the concept of the Common heritage of Mankind, see generally Kemal Baslar The Concept of the Common Heritage of Mankind in International Law (Brill 1998).

3 For a commentary on the legal issues on the Undertaking, see generally Bordwin $H$., The Legal and Political Implications of the International Undertaking on Plant Cenetic Resources, 12 Ecology Law Quarterly Vol. 12, 1053 (1985)

4 Rose, G, 'International Regimes for the Conservation and Control of Plant Genetic Resources, in International Law and the Conservation of Biological Diversity

5 Article 1

6 Murphy, S. Biotechnology and International Law, Harvard Journal of International Law, Vol. 42 (2001), 47. 
Neither is it clear whether existing international trade rules require labelling to notify consumers that a particular product is genetically engineered or modified. The development of a comprehensive international regime on biotechnology would help to establish the guidelines to assist with trade issues involving genetically modified products.

Inherent transnational character of biotechnology policy issues

While local or national in character, biotechnology policy issues have an intrinsic international character. One authors sums up the international elements in this observation:

As xenotransplants become more common, nationa regulations may be developed in some states to prevent animal viruses from spreading to humans. However, if comparable regulations do not exist in other states, leading to the risk of such viruses originating elsewhere and then traveling to the highly regulated states, then the national regulations will be undermined. In the field of immigration and refugee law, if the use of biotechnology for medical treatments in one group of states vastly outpaces development in other states, a new category of persons known as "medical refugees" may emerge. Doctors may also someday be able to screen individuals genetically for their disposition to engage in criminal behavior, which may tempt legislators to use this information to deny the admission of refugees on grounds of national security or safety. At the furthest extreme, if human cloning is not banned by some states, how should international law, including human rights law, treat humans that are cloned, or (deal with) hybrid mammals created in these states??

\section{The current international frame work for regulation of biotechnology}

There is no single comprehensive international instrument that regulates biotechnology and addresses concerns that are generally levelled against biotechnology. The existing law comprises a mosaic of mostly soft law instruments that seem to lack focus. It is possible to group the existing instruments into four broad categories that encompass: human rights protection, intellectual property rights protection, the protection of the environment and agriculture and novel food products. In this section we will examine briefly the instruments that make up the regulatory regime.

\section{The Human rights instruments}

UNESCO Declaration on the Human Genome and Human Rights

The Universal Declaration on the Human Genome and Human Rights was adopted by unanimous vote at the 29th session of UNESCO's General Conference on 11 November $1997^{8}$. It was subsequently endorsed by the United Nations Ceneral Assembly in 19989. In 1999, UNESCO adopted
Guidelines for the Implementation for the Declaration. The central element of the Declaration is its affirmation of the human rights of the individual and the primacy of the human rights, fundamental freedoms and human dignity and over 'research applications concerning the human genome, in particular in the fields of biology, genetics and medicine'. ${ }^{10}$ The notion of human dignity is central to the Declaration. Human dignity concerns the intrinsic character of the human person as such and the essence or value of the individual as a part of the human species. The focus of the Declaration on human dignity however defined is thus significant ${ }^{11}$.

In terms of regulation, the Declaration provides in Article 11 that:

Practices which are contrary to human dignity, such as reproductive cloning of human beings, shall not be permitted. States and competent international organizations are invited to co-operate in identifying such practices and in taking, at national or international level, the measures necessary to ensure that the principles set out in this Declaration are respected.

While stating that practices such as human cloning shall not be permitted, the Declaration does not go any further to provide any concrete directions for signatories. With statements such as: 'states shall take appropriate measures' or 'steps', the Declaration provides little or no foundation for a regulatory framework. The Declaration is well known and referred to frequently in human genome discussions. This notwithstanding the instrument as a 'declaration' is not in itself legally binding.

\section{UNESCO Declaration on Human Cenetic Data}

The Declaration adopted in 2003 aims to 'ensure the respect of human dignity and protection of human rights and fundamental freedoms in the collection, processing, use and storage of human genetic data, human proteomic data and of the biological samples from which they are derived'12 Article 19 provides for the sharing of the benefits arising from human genetic data in accordance with domestic law or policy and international agreements'. As in the case of the Declaration on

7 Ibid, 6o

8 Resolution $29 \mathrm{C} / 17$

9 CA Res/53/152 (December 1998)

10 Art. 10.

11 For a commentary on the Declaration see TAYLOR, A Globalization and Biotechnology: UNESCO and an International Strategy to Advance Human Rights and Public Health, American Journal of Law and Medicine, (1999), $\mathrm{n}^{\circ} 4$, p. 479-541 
Human Genome and Human Rights, this Declaration provides no binding legal obligations.

United Nations Declaration on Human Cloning

In March 2005, the United Nations General Assembly adopted Resolution 10333 on human cloning. The resolution was the result of a long and controversial debate in the Assembly. Unlike the unanimous declaration in the UNESCO Ceneral Conference, this resolution was adopted by 84 in favour to 34 against, with 37 abstentions. The substantive element in the Declaration is that probation of 'all forms of human cloning inasmuch as they are incompatible with human dignity and the protection of human life' While the Declaration is not legally binding, the strong opposition it attracted provides an important insight into the difficulties of adopting an international instrument on the issue of cloning. In explaining why China voted against the Declaration, the Chinese delegate explained that 'different countries varied in their understanding of the text's inherent moral, ethical and religious aspects, and it was regrettable that the Declaration failed to give effect to the concerns of those countries. He argued that the prohibitions contained in the text could be misunderstood as covering all forms of cloning. ${ }^{13}$

Council of Europe's Convention for the Protection of Human Rights and Dignity of the Human Being with Regard to the Application of Biology and Medicine: Convention on Human Rights and Biomedicine

This is the first and indeed only attempt to establish a binding European legal instrument that covers not all but at least some of the core areas of medicine. Unlike the United Nations and UNESCO instruments, the Council of Europe Convention on Human Rights and Biomedicine is legally binding. Parties to the Convention undertake to "protect the dignity and identity of all human beings and guarantee everyone, without discrimination, respect for their integrity and other rights and fundamental freedoms with regard to the application of biology and medicine'. ${ }^{14}$ Article 2 emphases the primacy of human dignity over the 'sole interest of society or science'. Article 11 prohibits discrimination on the basis of genetic make up while Article 12 and 13 restrict predictive genetic tests and intervention on the human genome respectively.

The Convention is a 'framework' instrument and leaves room for more specific instruments in the nature of 'additional protocols' to deal with more specific issues: So far three additional protocols have been adopted with a fourth on human genetics to be developed later. The current additional protocols are:
(1) The Additional Protocol to the Convention on Human Rights and Biomedicine on the Prohibition of Cloning Human Beings

The substantive section of this instrument is Article 1 which provides in very explicit terms as follows:

1. Any intervention seeking to create a human being genetically identical to another human being, whether living or dead, is prohibited.

2. For the purpose of this article, the term human being "genetically identical" to another human being means a human being sharing with another the same nuclear gene set.

As noted in the Explanatory Report to the Protocol, the instrument 'does not take a specific stand on the admissibility of cloning cells and tissue for research purposes resulting in medical applications'15 as such. However, the general tenure of the provisions seems to admit that 'cloning as a biomedical technique is an important tool for the development of medicine, especially for the development of new therapies'. The Explanatory Report therefore makes the point that the 'provisions in [the] Protocol shall not be understood as prohibiting cloning techniques in cell biology'.

(2) The Additional Protocol to the Convention on Human Rights and Biomedicine on the Transplantation of Organs and Tissues of Human Origin

This Protocol applies to the transplantation of organs and tissues of human origin carried out for therapeutic purposes. Its provisions applicable to tissues also apply to cells, including haematopoietic stem cells. ${ }^{16}$ However, the Protocol does not apply reproductive organs and tissue and neither does it apply to embryonic or foetal organs and tissues or to blood and blood derivatives. ${ }^{17}$

While Article 22 prohibits 'organ and tissue trafficking', Article 21 provides that the 'human body

12 Art. 1.

13 UN News release: http://www.un.org/News/Press/ docs/2005/galo333.doc.htm (23 May2005)

14 Art. 1

15 Explanatory Report, Additional Protocol to the Convention on Human Rights and Biomedicine on the Prohibition of Cloning Human Beings (ETS No. 168), para 4.

http://conventions.coe.int/Treaty/EN/Reports/Html/ 168.htm

16 Article 2.

17 Article 2(2) 
and its parts shall not, as such, give rise to financial gain or comparable advantage'. Civen the ban on organ and tissue trafficking, it is understandable that the Protocol further prohibits the making of 'financial gain or comparable advantage' from the human body and its parts'. The question of financial gain is however very problematic. The Protocol does not define 'financial gain or comparable advantage'. It is to be noted that Article 21 permits 'payments which do not constitute a financial gain or a comparable advantage, in particular:

- compensation of living donors for loss of earnings and any other justifiable expenses caused by the removal or by the related medical examinations;

- payment of a justifiable fee for legitimate medical or related technical services rendered in connection with transplantation;

- compensation in case of undue damage resulting from the removal of organs or tissues from living persons

(3) The Additional Protocol to the Convention on Human Rights and Biomedicine, concerning Biomedical Research

This Protocol covers the full range of research activities in the health field involving 'interventions' on human beings. However it does not apply to research on embryos in vitro; it applies to research on foetuses : and embryos in vivo. ${ }^{18}$ It requires any research to be 'scientifically justified', and to 'meet generally accepted criteria of scientific quality and to be carried out in accordance with relevant professional obligations and standards under the supervision of an appropriately qualified researcher'.(Article 8). The protocol further defines the conditions to be fulfilled in instances where the research involves persons who are not capable or able to provide valid and informed consent, and groups such as prisoners or expectant or nursing mothers.

In spite of its 'hard law' provisions, the Protocol also contains some soft law elements. For instance Article 6 provides that ' $[\mathrm{r}]$ esearch shall not involve risks and burdens to the human being disproportionate to its potential benefits'. (emphasis added). It further provides that ' where the research does not have the potential to produce results of direct benefit to the health of the research participant, such research may only be undertaken if the research entails no more than acceptable risk and acceptable burden for the research participant'.

The pProtocol anticipates developments in science. Article 35 thus provides that '[i]n order to monitor scientific developments, the ... Protocol shall be examined within (the relevant Committee)
... no later than five years from the entry into force ... and thereafter at such intervals as the Committee may determine.

\section{Biodiversity and the Protection of the Environment}

There is a number of instruments which directly relate to biodiversity and the environment in so far as biotechnology is concerned. These include:

\section{The Convention on Biological Diversity}

Adopted in 1992, the Biodiversity Convention is the most comprehensive international instrument relating to the conservation of biodiversity. The emphasis of the instrument however is not on biotechnology as such. The objectives of the Convention are stated as 'the conservation of biological diversity, the sustainable use of its components and the fair and equitable sharing of the benefits arising out of the utilization of genetic resources, including by appropriate access to genetic resources and by appropriate transfer of relevant technologies, taking into account all rights over those resources and to technologies, and by appropriate funding'. ${ }^{19}$ While Article 19 of the Convention specifically refers to issues of biotechnology and biosafety, the provisions are largely in the nature of 'soft law'. For instance the Contracting Parties undertake to 'provide for the effective participation in biotechnological research activities' particularly by developing countries. They also undertake to adopt 'all practicable measures to promote and advance priority access on a fair and equitable basis by Contracting Parties, especially developing countries, to the results and benefits arising from biotechnologies based upon genetic resources provided by those Contracting Parties'. On the specific issue of safety, the Convention only provides for the parties to 'consider the need for and modalities of a protocol setting out appropriate procedures, including, in particular, advance informed agreement, in the field of the safe transfer, handling and use of any living modified organism resulting from biotechnology that may have adverse effect on the conservation and sustainable use of biological diversity.'

\section{Cartagena Protocol on Biosafety}

Adopted in pursuance of the reactionary principle under Principle 15 of the Rio Declaration, the objective of this Protocol is 'to contribute to ensuring an adequate level of protection in the field of the safe transfer, handling and use of living modified

\section{Article 2}

19 Article 1. 
organisms resulting from modern biotechnology that may have adverse effects on the conservation and sustainable use of biological diversity, taking also into account risks to human health, and specifically focusing on transboundary movements.'20 The Protocol covers the 'transboundary movement, transit, handling and use of all living modified organisms that may have adverse effects on the conservation and sustainable use of biological diversity, taking also into account risks to human health' but excludes the 'transboundary movement of living modified organisms which are pharmaceuticals for humans that are addressed by other relevant international agreements or organisations'21 Apart from risk management ${ }^{22}$ and risk assessment ${ }^{23}$ issues, the Protocol also makes provisions for 'handling transporting, packaging and identification of modified organisms in order to avoid adverse effects on the conservation and sustainable use of biological diversity'. ${ }^{24}$ The Protocol also creates the Biotechnology Clearing House, in order to facilitate the exchange of information on Living Modified Organisms and to assist countries to implement the Protocol.

\section{Law of the Andean Community}

The Andean Community is a sub-regional organization that comprises South America: Bolivia, Colombia, Ecuador, Peru and Venezuela created through the Cartagena Agreement. In 2000 The Community adopted 'Decision 486', which sets out common rules for the granting, implementation and enforcement of a wide range of IPRs. in the five Member States with direct reference to the Convention on Biological Diversity.

International Plant Protection Convention

Originally adopted in 1951 and revised in 1997, the International Plant Protection Convention (IPPC) the main objective of this instrument isaims to implement a secure joint and effective action to prevent the spread and introductions of pests of plants and plant products, and to promote appropriate measures for their control. It is a multilateral agreement which is legally binding.

\section{Food and Agriculture}

The main international instrument regarding biotechnology issues in food and agriculture is the International Treaty on Plant Cenetic Recourses for Food and Agriculture. While Thethe preamble of the instrument recognisesrecognizes that plant genetic resources for food and agriculture are the raw materials indispensable for crop genetic improvement, whether by means of farmers' selec- tion, classical plant breeding or modern biotechnologies, and are essential in adapting to unpredictable environmental changes and future human needs'. However, the focus of the treaty is on plant genetic resources as such and not on biotechnology.

The most comprehensive international instruments concerning biotechnology in food and agriculture are the several European Directives and Regulations. For example, Regulation (EC) No 1830/2003 of the European Parliament and of the Council provides ' $a$ framework for the traceability of products consisting of or containing genetically modified organisms (GMOs), and food and feed produced from GMOs, with the objectives of facilitating accurate labelling, monitoring the effects on the environment and, where appropriate, on health, and the implementation of the appropriate risk management measures including, if necessary, withdrawal of products'. (Article 1) The Regulation applies at all stages of the placing on the market, to: (a) products consisting of, or containing, CMOs, placed on the market in accordance with Community legislation; (b) food produced from GMOs, placed on the market in accordance with Community legislation; (c) feed produced from GMOs, placed on the market in accordance with Community legislation.(Article 2). Commission Regulation (EC) No 49/2000 of 10 January 2000 deals with issues of labeling of food products and the establishment of a de minimis threshold for the adventitious presence in food ingredients of material derived from the certain genetically modified food products. Regulation (EC) No 1829/2003 of 22 September 2003 on genetically modified food and feed provides the basis for ensuring a high level of protection of human life and health, animal health and welfare, environment and consumer interests in relation to genetically modified food and feed, whilst ensuring the effective functioning of the internal market; and lays down Community procedures for the authorisation and supervision of genetically modified food and feed. It further deals with labelling of genetically modified food and feed. Regulation (EC) No 258/97 (concerning novel foods and novel food ingredients) applies foods and food ingredients containing or consisting of genetically modified organisms within the meaning of Directive 90/220/EEC.
20 Article 1
21 Article 5
22 Article 15
23 Article 16
24 Article 18 


\section{Inteliectual Property}

Since biotechnology inherently involves the use of biological systems, living organisms, or related derivatives to make or modify products or processes, it invariably has intellectual property implications. Article 27 of the WTO Agreement on TradeRelated Aspects of Intellectual Property Rights (TRIPS Agreement) excludes patentability for diagnostic, therapeutic and surgical methods for the treatment of humans or animals. It allows for the exclusion of 'plants and animals other than microorganisms, and essentially biological processes for the production of plants or animals other than nonbiological and microbiological processes.' However, it permits Members to 'provide for the protection of plant varieties either by patents or by an effective sui generis system or by any combination thereof.' The European Directive 98/44/EC of July 1998 also deals with the 'legal protection of biotechnological inventions',

\section{The normative focus of regulation in biotech- nology}

What is the normative issue in the regulation of biotechnology? There is confusion in international law as the focus of regulation. It is not clear if the focus should be on intellectual property protection or public accountability. As a logical development of man's creative abilities, biotechnology offers an unparalleled potential for mankind. It represents an excellent avenue that can be applied to many areas of food and agriculture, medicine and the invention of new drugs. It offers tremendous potential to address real problems facing the many millions of people particularly in the developing countries who face constant starvation. But like most other phenomena known in human history, the unregulated application of biotechnology has potential adverse implications also.

If one makes intellectual property rights protection the focus in biotechnology, then the claim by biotechnology industries that their methods and products are simply innovations and amount to no more than man's evolutionary and sometimes revolutionary approaches to inventions and progress are correct. The issue of intellectual property protection cannot and should be dismissed too lightly. As noted earlier, to the extent that biotechnology involves the manipulation of biological systems, living organisms, or related derivatives to make or modify products, it invariably involves inventions and matters issues of intellectual property rights. Once we accept the need to protect intellectual property rights generally in other areas of human activity, then logically we must also acceft the right to protect new inventions through the ise of biotechnology.

On the other hand if one makes public accountability and regulation as the focus for regulation, then the issues are quite different. The issue central question becomes the scope and extent necess $a r y$ to regulate biotechnology without stifling human progress and new inventions. The attraction of making accountability the focus of regulation is that it is capable of providing a better avenue for balance between the competing demands of corporate profits through intellectual property rights protection, and the need to ensure community protection through a credible system of transparency and accountability.

Whatever focus one chooses as the basis of regulation of biotechnology, the reality is that there is no credible international instrument that regulates biotechnology activities as such apart from the European regulations and directives. Perhaps given the history of Europe, the relative clarity with which the Europeans have approached the question of biotechnology is understandable. But their approach must provide important lessons for the rest of international community. The current nternational legal frame work for the regulation of biotechnology is far from desirable. Apart from the absence of any stringent system of accountability on an international basis, the current regime lacks a comprehensive or holistic approach. The reality of biotechnology is that it is not only international in character, but as the scientific knowledge of mankind advances, so would the new biotechrological inventions increase. Given the predictable incremental advances in man's inventive ability, there would seem to be an urgent need to develop appropriate instruments that comprehensively address the question of biotechnology in all asfrects. The development of the WTO Agreement ard its related multilateral and plurilateral agreements concerning all aspects of trade suggest clearly that it is possible to adopt a comprehensive regime on biotechnology. Indeed it is arguable that it is potentially easier to develop a comprehensive trea:y on biotechnology because most states have in place national legislation that deals with some aspects of biotechnology already, unlike what negotiators would have encountered during the talks to de velop the WTO agreements. The prospects for a conprehensive international regulatory instrument on biotechnology are rather good. The international community must adopt an accountability-oriented focus for regulation and develop such an instrument accordingly. 